\title{
Heart rate and haemodynamics after autonomic blockade in infants and children ${ }^{1}$
}

\author{
G. R. Cumming and G. H. Mir \\ From The Children's Hospital of Winnipeg, and The Departments of Pediatrics \\ and Medicine, University of Manitoba, Canada
}

In order to assess the role of the autonomic system in the age differences in heart rate, propranolol $0.2 \mathrm{mg} . / \mathrm{kg}$. and atropine $30 \mu \mathrm{g} . / \mathrm{kg}$. were given to I03 infants and children during the course of heart catheterization. Mean control minute heart rate varied from $I 18$ at age $I$ year to $8 I$ at age 16 years. Heart rate after drugs was termed intrinsic heart rate after fose, and the mean varied from $I 39$ at age $I$ to 102 at age 16 years. After propranolol alone, mean heart rate was $I 20$ at age $I, 7 I$ at age 16 , and after atropine corresponding rates were 162 and 128 . The scatter in predicting heart rate from age was not lessened by autonomic blockade, suggesting that interindividual variations in heart rate are not entirely dependent on different levels of autonomic function. The inverse relation between heart rate and age persisted after autonomic blockade, indicating that different levels of autonomic function are not responsible for the age differences in heart rate. The most important determinant of the heart rate after blockade was the initial control heart rate. Increases in cardiac index followed autonomic blockade in patients over 4 years of age and in patients without intracardiac shunts, while stroke index decreased, and femoral artery pressure increased $2 / 7 \mathrm{~mm}$. $\mathrm{Hg}$.

Heart rate in the intact animal is determined by the basic rate of impulse formation at the pacemaker centre, and modifying factors such as neurohumoral control, body temperature, and thyroid function. In children, the average resting heart rate declines from 130 beats a minute or higher at I month of age to 80 beats a minute at 16 years of age (Keith, Rowe, and Vlad, 1958). A difference in autonomic control may contribute to the variation in heart rate with age. Autonomic blockade of the heart can now be effectively and safely produced with atropine and propranolol, partially isolating the heart from the chronotropic effects of vagal and sympathetic stimulation (Jose, 1966). In order to assess the influence of autonomic control on the heart rate of children of different ages, atropine and propranolol have been given to I03 infants and children at the time of diagnostic heart catheterization studies. The alterations in heart rate, systemic and pulmonary arterial pressures, and cardiac output after autonomic blockade, form the basis of this report.

Received 9 March 1970.

1 Supported in part by the Manitoba Heart Foundation.

\section{Subjects and methods}

Only children with defects of mild to moderate severity were included in the study. None was receiving digoxin, none was in congestive heart failure, and haemodynamic abnormalities were considered mild or moderate. In the patients with ventricular septal defects, the ratio of pulmonary to systemic flow was under 1.5 . In patients with valvular stenosis, peak systolic pressure gradients were less than $30 \mathrm{~mm}$. Hg. The number of patients

TABLE I Age-group and number of subjects by diagnosis

\begin{tabular}{llrrr}
\hline & $\begin{array}{l}\text { Age-group } \\
\text { Diagnosis }\end{array}$ & & & \\
& $<2$ years & $2-5$ years & $6-16$ years & Total \\
\hline Shunt absent & & & & \\
$\quad$ Normal and miscellaneous & 3 & 3 & 8 & 14 \\
Pulmonary stenosis & 8 & 11 & 6 & 25 \\
Aortic stenosis & 1 & 2 & 2 & 5 \\
Coarctation & 1 & 1 & 0 & 2 \\
All patients - shunt absent & 13 & 17 & 16 & 46 \\
\hline Left-to-right shunt & & & & \\
Ventricular septal defect & 9 & 16 & 5 & 30 \\
Atrial septal defect & 8 & 9 & 4 & 21 \\
Persistent ductus arteriosus & 1 & 5 & 0 & 6 \\
All patients - shunt present & 18 & 30 & 9 & 57 \\
\hline Total patients & 31 & 47 & 25 & 103 \\
\hline
\end{tabular}


in each diagnostic category and their ages are given in Table $I$.

Since the interpretation of the data presented must include recognition of the possible effects of sedation required for the catheterization procedure, the sedation regimen used in this laboratory is shown in Table 2. This sedation was usually sufficient to allow the measurement of haemodynamics during light sleep in children under 7 years of age. Children with obvious apprehension were not included in the study.

TABIE 2 Sedation for heart catheterization

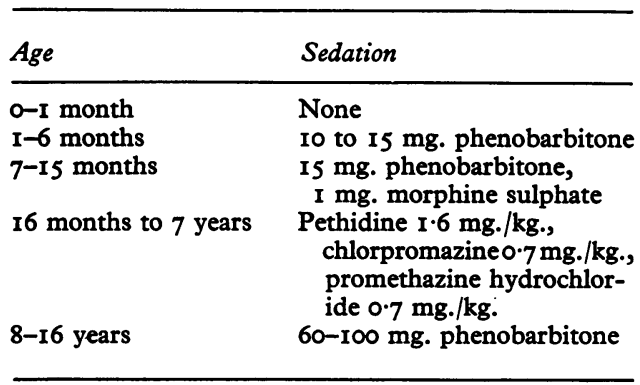

Atropine sulphate (30 $\mu \mathrm{g} . / \mathrm{kg}$.) and propranolol $(0.2 \mathrm{mg} . / \mathrm{kg}$.) were given through a cardiac catheter into the venous circulation. Forty-five subjects received atropine first, followed by propranolol in 5 to ro minutes; 48 subjects received propranolol initially, followed in 5 to ro minutes by the atropine; and ro subjects received both drugs together. Haemodynamics were measured 5 to ro minutes after both drugs were given. Factorial analysis indicated that the order of giving the drugs had no influence on heart rate, cardiac output, or systemic arterial pressures, and accordingly all subjects were grouped together for analysis of the changes produced by autonomic blockade.

Heart rate was obtained from a 20-second record of the electrocardiogram. The heart rate after autonomic blockade has been called intrinsic heart rate using the terminology of Jose (r966), and the rate before drugs has been termed control rate. Femoral and pulmonary artery pressures were monitored with Statham 23db pressure transducers; cardiac output was determined with the indicator dilution method using indocyanine green dye. The indicator curves were calibrated with the dynamic method (Shinebourne, Fleming, and Hamer, 1967), and left-to-right shunts were quantitated from the curves (Carter et al., 1960).

Temperature factors were not well controlled during heart catheterization procedures, though the air-conditioned laboratory was maintained at approximately $24^{\circ} \mathrm{C}$., and the younger infants who are more susceptible to loss of body heat were covered with a warm flannel blanket, and in some instances were placed on a mattress with circulating water and heat exchanger.
TABLE 3 Heart rate vs age

\begin{tabular}{rrlllll}
\hline $\begin{array}{l}\text { Age } \\
(y r .)\end{array}$ & $\begin{array}{l}\text { No. of } \\
\text { subjects }\end{array}$ & $\begin{array}{l}\text { Control } \\
\text { heart } \\
\text { rate }\end{array}$ & $\begin{array}{l}\text { Intrinsic } \\
\text { heart } \\
\text { rate }\end{array}$ & $\begin{array}{l}\text { Change in rate Atropine } \\
\text { from control }\end{array}$ & $\begin{array}{l}\text { Propranolol } \\
\text { alone } \\
\text { alone }\end{array}$ \\
\hline $0-1 \cdot 0$ & 15 & $118 \pm 15$ & $139 \pm 15$ & $21 \pm 7$ & $162 \pm 28$ & $120 \pm 20$ \\
$1 \cdot 1-2 \cdot 0$ & 16 & $112 \pm 10$ & $131 \pm 16$ & $19 \pm 18$ & $130 \pm 11$ & $110 \pm 12$ \\
$2 \cdot 1-5 \cdot 0$ & 47 & $99 \pm 11$ & $123 \pm 17$ & $24 \pm 15$ & $140 \pm 16$ & $92 \pm 13$ \\
$5 \cdot 1-8 \cdot 0$ & 18 & $88 \pm 14$ & $119 \pm 16$ & $31 \pm 23$ & $137 \pm 27$ & $88 \pm 12$ \\
$8 \cdot 1-16$ & 7 & $81 \pm 15$ & $102 \pm 9$ & $21 \pm 12$ & $128 \pm 4$ & $71 \pm 18$ \\
\hline
\end{tabular}

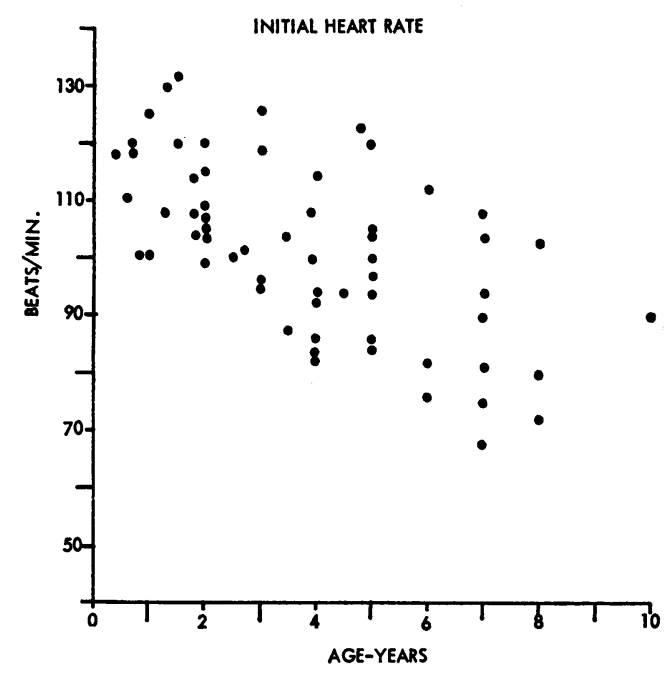

FIG. I Control heart rate vs age.

FIG. 2 Intrinsic heart rate vs age. Rate after propranolol and atropine.

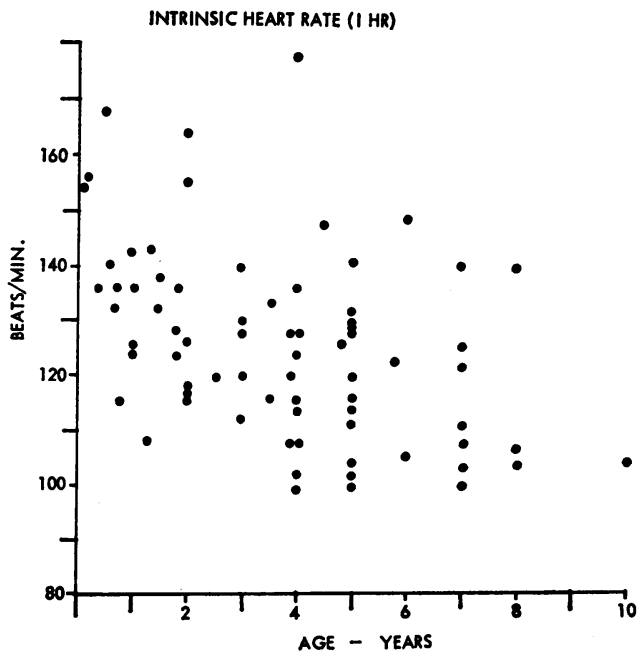




\section{Results}

Heart rate Mean heart rates before and after autonomic blockade were subdivided according to age and are presented in Table 3. As expected, control rate was highest in the younger subjects. The mean changes in heart rate varied from 19 to 31 beats a minute for the different age-groups. Factorial analysis indicated that the intrinsic heart rate was dependent on the control rate and the age of the subject, but not on diagnosis. The control rate and the intrinsic heart rate are plotted against age in Fig. I and 2. The control rate was significantly correlated to age $(r=-0.64)$, with a standard error of prediction of 12 per cent. The intrinsic rate was also significantly correlated with age $(r=-0.39)$, with a standard error of prediction of 13 per cent of the mean. Fig. I and 2 and the regression studies indicated that the intrinsic heart rate showed slightly more scatter than the control heart rate in relation to age. The error of predicting heart rate from age was not lessened by autonomic blockade.

The change in heart rate was subjected to further analysis. Fig. 3 shows that the change in rate was greatest in the subjects with the slowest control heart rate. Linear regression analysis showed that the change in rate was inversely related to the control rate $(r=$ $-0.49, \mathrm{p}<0.01$ ). The per cent change in rate was also inversely related to the control heart rate $(r=-0.58, p<0.01)$. Adding age to these regression equations did not increase the cor-

FIG. 3 Change in heart rate after autonomic blockers vs initial heart rate. under 4 years of age, $\bigcirc$ over 4 years of dge.

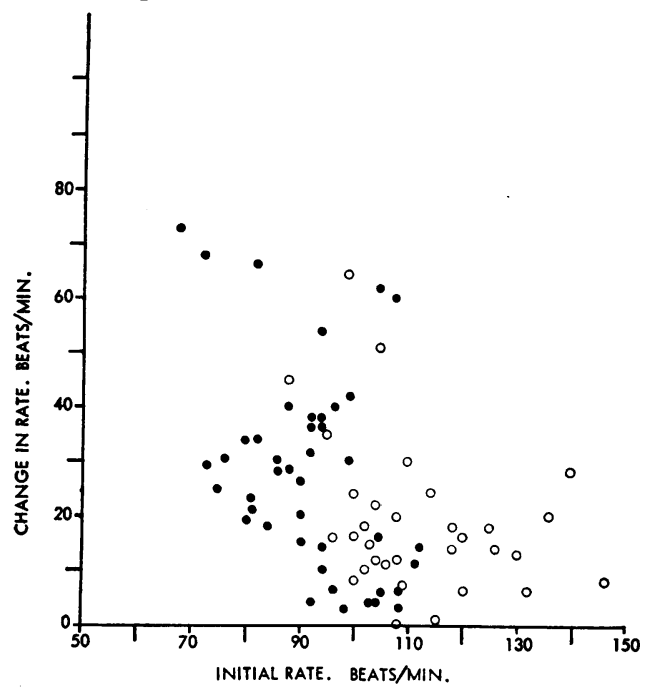

relation coefficient or reduce the standard error of prediction of the change in rate, and the $t$ ratio for the regression coefficient for age did not reach statistical significance. Therefore, the control heart rate was more important than the age in determining the change in rate.

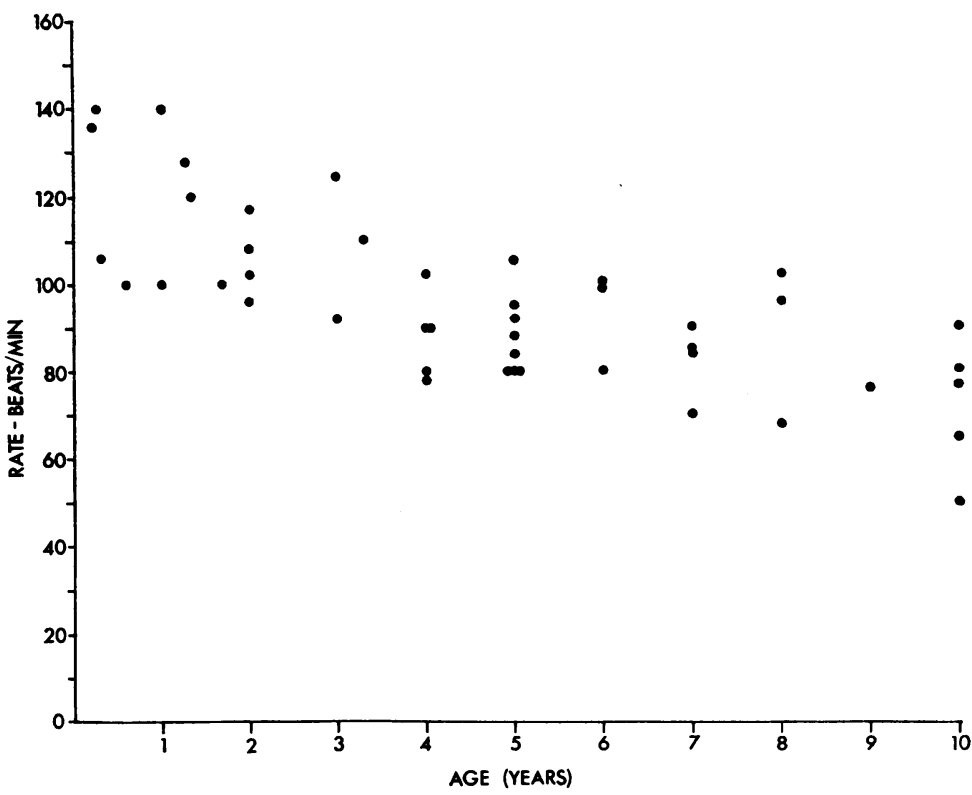

FIG. 4 Heart rate after propranolol alone vs age.

FIG. 5 Heart rate after atropine alone vs age.

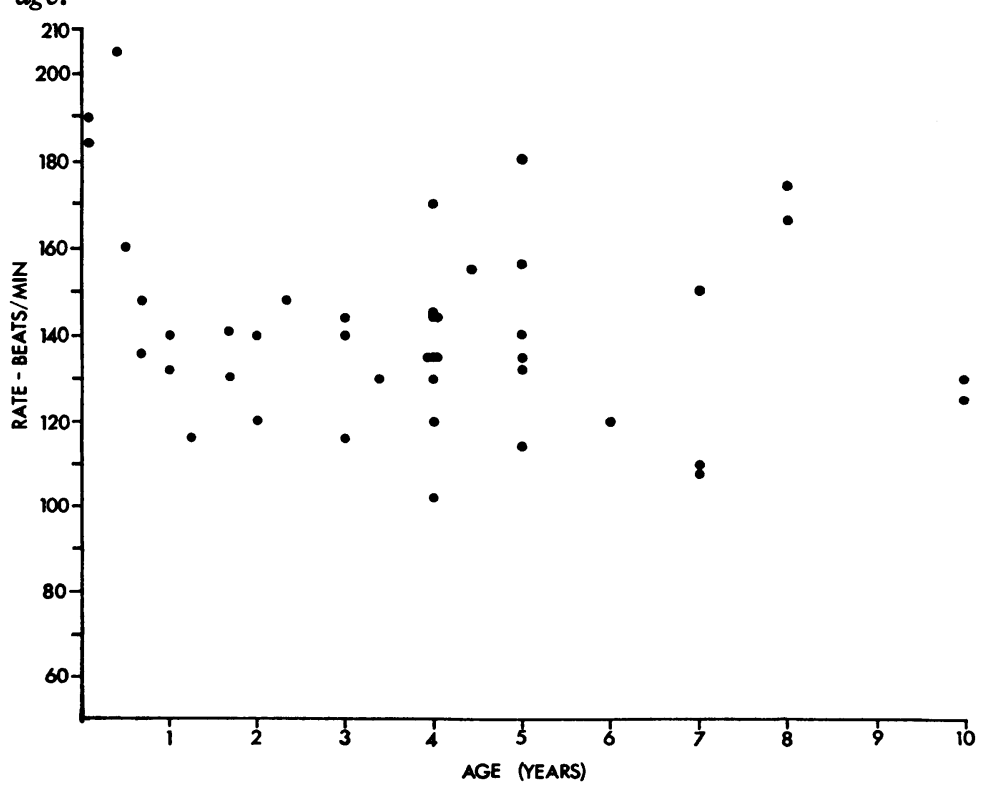


Heart rate after atropine alone showed conconsiderable scatter when plotted against age (Fig. 5), and the correlation coefficient was only $-0.22(p<0.05)$. On the other hand, when heart rate after propranolol alone was plotted against age (Fig. 4) there was a higher correlation $(r=0.68, p<0.001$, standard error of prediction $14 \%$ of the mean).

Cardiac index Cardiac index tended to be higher in those patients over 4 years of age and in those without shunts. Table 4 indicates that the control index was 18 per cent higher in patients without a shunt compared to those with a shunt, and that in the patients without a shunt the mean cardiac index was increased by 23 per cent after drugs. Cardiac index was higher before and after drugs in patients over 4 years of age compared with those under 4 years of age. Significant increases in the mean cardiac index after the autonomic blockade were noted only in patients without a shunt and in those over 4 years of age.

Stroke index Stroke index was significantly lower after autonomic blockade as the cardiac index did not increase in proportion to the heart rate. Factorial analysis indicated that the change in stroke index was independent of age and diagnosis.

Pressures Factorial analysis indicated that control femoral artery pressure was not affected by age or the presence or absence of a shunt. Table 5 indicates that there was no significant change in femoral artery systolic pressure after autonomic blockade, while both diastolic and mean pressures showed small increases.

The mean of the control pulmonary artery pressures was $5 \mathrm{~mm}$. higher in those patients with shunts. The autonomic blockade increased mean pulmonary artery pressure by 3 and $4 \mathrm{~mm}$. in each group, but none of the mean changes reached statistical significance. Only 7 of the subjects studied had pulmonary artery systolic pressure over $40 \mathrm{~mm}$. $\mathrm{Hg}$.

Left-to-right shunts The magnitude of the left-to-right shunt expressed either as absolute shunt flow or as a percentage of pulmonary blood flow was not significantly altered by the drugs.

\section{Discussion}

There has been no satisfactory explanation of the normal tachycardia of infants. Two possibilities are that the infant has a higher sympathetic tone or a reduced vagal tone. After both $\beta$-adrenergic and cholinergic inhibition of the
TABLE 4 Cardiac index (litres/min./m. ${ }^{2}$ )

\begin{tabular}{lllll}
\hline & Control & Drug & Change & p value \\
\hline No shunt & $4.46 \pm 0.80$ & $4.88 \pm 1 \cdot 19$ & $+0.42 \pm 0.38$ & $<0.01$ \\
Shunt & $3.66 \pm 0.96$ & $3.76 \pm 1.38$ & $+0.10 \pm 0.25$ & $>0.05$ \\
Age <4 yr. & $3.73 \pm 1.05$ & $3.81 \pm 1.15$ & $+0.08 \pm 0.33$ & $>0.10$ \\
Age >4 yr. & $4.38 \pm 0.77$ & $4.84 \pm 1.47$ & $+0.46 \pm 0.51$ & $<0.05$ \\
\hline
\end{tabular}

TABLE 5 Mean changes - all patients

\begin{tabular}{|c|c|c|c|c|}
\hline & Control & Drug & Change & $p$ value \\
\hline Heart rate (beats/min) & $102 \pm 17$ & $124 \pm 18$ & $+22 \pm 17$ & $<0.001$ \\
\hline Cardiac index $\left(1 . / \mathrm{min} . / \mathrm{m.}^{2}\right)$ & $4.06 \pm 0.98$ & $4 \cdot 32 \pm I \cdot 4 I$ & $+0.26 \pm 0.87$ & $<0.05$ \\
\hline Stroke index (ml./beat $\left./ \mathrm{m}^{2}{ }^{2}\right)$ & $40 \pm 12$ & $35 \pm 13$ & $-5 \pm 8$ & $<0.01$ \\
\hline $\begin{array}{l}\text { Femoral artery systole } \\
(\mathrm{mm} . \mathrm{Hg})\end{array}$ & III \pm 15 & $113 \pm 17$ & $+2 \pm 13$ & $>0.1$ \\
\hline $\begin{array}{l}\text { Femoral artery diastole } \\
(\mathrm{mm} . \mathrm{Hg})\end{array}$ & $58 \pm 8$ & $65 \pm 11$ & $+7 \pm 10$ & $<0.01$ \\
\hline $\begin{array}{l}\text { Femoral artery mean } \\
(\mathrm{mm} . \mathrm{Hg})\end{array}$ & $76 \pm 10$ & $82 \pm 12$ & $+6 \pm I I$ & $<0.01$ \\
\hline $\begin{array}{l}\text { Pulmonary artery systole } \\
(\mathrm{mm} . \mathrm{Hg})\end{array}$ & $21 \pm 7$ & $23 \pm 7$ & $+2 \pm 4$ & $>0.1$ \\
\hline $\begin{array}{l}\text { Pulmonary artery diastole } \\
(\mathrm{mm} . \mathrm{Hg})\end{array}$ & $9 \pm 3$ & $12 \pm 4$ & $+3 \pm 4$ & $>0.1$ \\
\hline $\begin{array}{l}\text { Pulmonary artery mean } \\
(\mathrm{mm} . \mathrm{Hg})\end{array}$ & $14 \pm 4$ & $17 \pm 6$ & $+3 \pm 4$ & $>0.1$ \\
\hline
\end{tabular}

heart, the heart rate of the infants was still distinctly higher than those of the older children. The negative correlation between heart rate and age persisted despite the probable elimination of most of the cholinergic and sympathetic effects. While the pharmacological blockade is a competitive one, and with the doses used is not complete, the dose of propranolol was sufficient to prevent any positive chronotropic effects from a bolus of $3 \mu \mathrm{g}$. isoprenaline, and unpublished studies carried out in this laboratory have indicated that there are no further increases in heart rate when the dose of atropine is increased beyond $30 \mu \mathrm{g} . / \mathrm{kg}$.

The combination of cholinergic and $\beta$ adrenergic inhibition did not reduce the scatter in heart rate or reduce the standard error of predicting heart rate from age, suggesting that variations in sympathetic and parasympathetic tone are not the major factors responsible for interindividual variations in the heart rate of children under the conditions of this study. Criticisms of the current study would include the necessity to use drugs to obtain prior sedation of the subjects, the effect of these on intrinsic heart rate not being known, and the failure to have strict control over other variables such as body temperature. The variety of diagnoses and haemodynamic abnormalities posed additional problems, yet only patients with relatively mild 
haemodynamic changes were used in this study, and factorial analysis indicated that diagnosis did not affect the heart rate results.

We have not studied the reproducibility of intrinsic heart rate in our patients, but Jose (I966) has reported it to be remarkably constant $( \pm 2 \%)$. Conway, Fowler, and Bloom (1969) found intrinsic heart rate varied from day to day by up to 15 beats a minute, and were unable to confirm the consistency reported by Jose ( 1966 ) in I 9 patients with heart disease. Jose found intrinsic heart rate to be increased with fever, thyrotoxicosis, salicylate and corticoid administration, while myocardial, coronary, rheumatic, and congenital heart disease patients had lower values for intrinsic heart rate (details of the latter patients have not been reported). $\mathrm{He}$ also noted that those with low intrinsic rate values were patients with more severe forms of heart disease.

Additional factors affecting intrinsic heart rate may be body build and physical fitness, slower rates occurring in the more fit subjects (Sutton et al., 1967), and more tachycardia with atropine in the asthenic subjects (Nalefski and Brown, 1950).

Patients with Down's syndrome were purposely excluded from this study, as Harris and Goodman (1967) have reported an increased sensitivity to atropine in patients with 2 I trisomy.

$\beta$-adrenergic blockade alone reduced the scatter in the individual heart rates plotted against age, but did not alter the inverse relation of heart rate to age. This suggests, (a) that some of the interindividual variations in heart rate are due to different levels of $\beta$-adrenergic activity, and (b) that the more rapid heart rates in the younger children are not primarily due to different levels of $\beta$-adrenergic activity.

Cholinergic inhibition alone produced quite variable effects on heart rate with considerable scatter in the plot of rate vs age. One 4-monthold infant had a heart rate of 205 beats a minute. The causes for the scatter in rate after atropine are not apparent, though dose response differences and time factors were not studied.

The results suggest that the age differences in the heart rates of children are not primarily due to different levels of autonomic control. The decline in heart rate with age seems to be due to age changes in the frequency of depolarization in pacemaker tissue. After 'total' autonomic blockade, heart rate increases, and the slower the initial rate, the greater this increase regardless of age.

\section{References}

Carter, S. A., Bajec, D. F., Yannicelli, E., and Wood, E. H. (1960). Estimation of left-to-right shunt from arterial dilution curves. Fournal of Laboratory and Clinical Medicine, 55, 77.

Conway, N., Fowler, J. M., and Bloom, S. (1969). Heart rate after combined vagal and sympathetic blockade in patients with heart disease. British Heart fournal, 31, 591.

Harris, W. S., and Goodman, R. M. (1967). A pharmacogenetic abnormality involving autonomic receptors in Down's syndrome. Clinical Research, 15, 407.

Jose, A. D. (1966). Effect of combined sympathetic and parasympathetic blockade on heart rate and cardiac function in man. American fournal of Cardiology, 18, 476.

Keith, J. D., Rowe, R. D., and Vlad, P. (1958). Heart Disease in Infancy and Childhood, p. 734. Macmillan, New York.

Nalefski, L. A., and Brown, C. F. G. (1950). Action of atropine on the cardiovascular system in normal persons. Archives of Internal Medicine, 86, 898.

Shinebourne, E., Fleming, J., and Hamer, J. (1967). Calibration of indicator dilution curves in man by the dynamic method. British Heart fournal, 29, 920.

Sutton, J. R., Cole, A., Gunning, J., Hickie, J. B., and Seldon, W. A. (1967). Control of heart-rate in healthy young men. Lancet, $2,1398$. 